\title{
La medicina popular. ¿Los límites culturales del modelo médico? ${ }^{1}$
}

La medicina popular no es tanto una realidad en sí misma como un concepto desarrollado en el contexto de un saber específico, el de la medicina occidental. Aunque, posteriormente, debido a esa constante danza de préstamos que se produce entre disciplinas, haya constituido también una herramienta conceptual de la antropología. Pero ¿qué es un concepto? y, no menos importante, ¿cómo operar ante él?

Canguilhem (1955: 5-7 y 169; 1989: 177) nos ha mostrado, partiendo de la epistemología de Bachelard, que un concepto no es sólo una palabra, sino fundamentalmente una problemática sujeta a revisiones y rectificaciones. Cuando se maneja un concepto se ponen en juego ciertas orientaciones y se señalan determinados enigmas que se consideran social y científicamente pertinentes pero a costa también de excluir otras opciones posibles. Por otro lado, para que un concepto adquiera sentido y valor en una disciplina ha de mostrar coherencia en una teoría y, por tanto, en su relación con los demás conceptos que la componen. Analizar un concepto es, entonces, sumergirse en el contexto en donde éste adquiere un significado relevante y, también, arrojar luz sobre las conexiones explícitas e implícitas que en torno a él se articulan. Pero ¿qué alumbra esta idea en el análisis de la noción de medicina popular?

Hablar de medicina popular implica también definir una orientación en donde se supone la existencia de una o varias medicinas que constituyen saberes diferenciados de la medicina científica o biomedicina. Conlleva dibujar una discontinuidad en donde el concepto adquiere coherencia: aquí las medicinas populares diversas, variopintas y culturalizadas; allá la Medicina homogénea, universal y asocial. Curiosamente, la primera ha sido estudiada por la antropología pero fue inventada por un médico. La segunda, paradójicamente, tuvo a la antropología por una de sus ciencias básicas. Sin embargo, lo que aquí resulta relevante es que el propio

1 Este artículo es fruto de una larga colaboración entre ambos autores. Retoma y amplía cuestiones esbozadas por ambos en un libro reciente (1993), y que, por las limitaciones editoriales, no pudieron desarrollarse plenamente. 
concepto ha encerrado también una demarcación para la antropología: la pertinencia de estudiar lo folk y lo inapropiado de indagar en el interior de la biomedicina.

Por esta razón, una problemática como la de la medicina popular se convierte, de hecho, en un concepto que lejos de ser aséptico es también 'político' tanto para la medicina como para la antropología. Como veremos en este artículo, supone aceptar una demarcación que viene dada históricamente no por las ciencias sociales sino por la constitución del propio modelo médico en su campaña por aculturar los saberes populares e ilustrados sobre la salud y la enfermedad. Por otro lado, permite legitimar, por omisión, la universalidad, la asocialidad, la ahistoricidad, el biologicismo y la eficacia pragmática que caracterizan al modelo médico (Menéndez, 1978).

Nuestro objetivo es mostrar que la noción de medicina popular -junto a términos usados como sinónimos: folklore médico, medicina tradicional, medicina primitiva-, es una invención epistemológica creada inicialmente con el propósito de legitimar el modelo médico. Y para ello analizaremos cuatro redefiniciones que se han elaborado de este concepto: la noción de medicina popular de Pitré, el desarrollo de categorías como folk-medicine y medicina primitiva, su disolución del brazo de la antropología de la medicina y la clinically applied anthropology norteamericana, y su recuperación crítica a partir de la noción de saberes populares subaltermos. Como se podrá observar, hablar de invención o de construcción epistemológica no es original ni exclusivo sino que, más bien, constituye una idea fuertemente arraigada en la antropología de la medicina contemporánea frente a las posiciones de las etno-nosografías del folklore positivista. Incluso el propio surgimiento y expansión de la especialidad puede percibirse como resultado de la crítica y la disolución de esa demarcación entre lo folk y lo científico que prefigura la noción de medicina popular.

\section{LA INVENCIÓN BIOMÉDICA DE LA MEDICINA POPULAR}

El término medicina popular se extendió por Europa como consecuencia de la influencia de Giuseppe Pitré ${ }^{2}$. Con anterioridad los términos utilizados eran errores médicos, supersticiones vulgares, superche-

\footnotetext{
2 Véase la obra de Pitré, Medicina Popolare Siciliana (1896). Su influencia en Espaǹa es evidente, consúltese Pérez Vidal (1945); la obra de Castillo de Lucas (1952 y 1952a) y, más recientemente, de Erkoreka (1985).
} 
rías, etc..., y habían dado lugar a una amplia literatura desde el siglo xvı que, a principios del XIX, se fue articulando con el folklore ${ }^{3}$.

Ciertamente, la medicina había tenido un interés precoz por los saberes populares puesto que en ellos veía una fuente de remedios empíricos (y a veces no tan empíricos) o de fórmulas adivinatorias. La multiplicación de Tesoros de los pobres y de diferentes textos de divulgación pone de manifiesto una enorme ambigüedad entre la recuperación de todo tipo de prácticas y la inculcación de nuevos discursos. Representan un esfuerzo por escribir y sistematizar parte del acervo popular y con ello se constituyen como textos etnográficos que reflejan un conocimiento de primera mano, obtenido de un número mayor o menor de experiencias con los pacientes y sus familias ${ }^{4}$.

Junto a esta dimensión etnográfica que deriva no poco del itinerario del galeno o del cuidador de casa en casa, otros médicos desarrollan otro género descriptivo de naturaleza etnográfica: las topografias médicas, basadas en los criterios descriptivo-interpretativos establecidos en los hipocráticos Los Aires, las Aguas y los Lugares (1986: II, 39-88), y que son descripciones holísticas de las relaciones entre ambiente y enfermedad'. Las topografías no son, como los recetarios, el fruto de experiencias individuales, sino intentos de construir un modelo a partir de la guía de trabajo implícita en el texto hipocrático, o de las desarrolladas posterior-

${ }^{3}$ Véase Guichot y Sierra (1984), en donde hemos encontrado los siguientes términos correspondientes a títulos de libros sobre el tema traducidos al castellano: supersticiones, creencias, usos (en Italia), medicina mágica, arte popular de curar, medicina casera.

${ }^{4}$ La literatura de divulgación se desarrolló precozmente en el siglo XVI para difundir la ciencia médica entre la población culta (Wear, 1992). Como ejemplo puede verse la obra de Andrew Boorde, The Breviarie of Health: wherein doth folow remedies for all manner of sicknesses $\&$ diseases, the which may be in Man or Woman. Expressing the obscure termes of Greke, Araby, Latin, Barbary and English, concerning Phisick and Chirurgerie (Printed at London by Thomas East. 1587), publicada inicialmente en 1547 y que fue el primer escrito de su género en inglés. Su propósito era posibilitar la comprensión de médicos cirujanos y profanos de términos y prácticas, muchas de ellas populares que el texto recoge. Muchos de estos textos ponen de manifiesto que son compilaciones de experiencias personales a lo largo de muchos años de práctica. Ello no obsta para que a menudo sus contenidos se copiasen. Un tratamiento exhaustivo de esta literatura en la España del xvir está en la tesis de doctorado de Enrique Perdiguero (1990, 1992).

' El interés de las topografias médicas como fuentes de saber etnográfico ha sido destacado por Silvia Carrasco (1989) y por Llorenç Prats (1990). El tratamiento más completo de las mismas en nuestro país ha sido el objeto de la tesis de doctorado de Cristina Larrea (1994), que explota esta fuente para establecer la penetración del neohipocratismo en la cultura y los saberes populares. 
mente (Larrea, 1994: 75-90). En ellas se ponen de manifiesto las relaciones dinámicas entre ambiente y enfermedad y se incluyen los errores vulgares como obstáculos a la penetración de un discurso médico que se propone mejorar las condiciones de salubridad. El objetivo de las topografías y los recetarios es sensiblemente distinto. Los segundos descontextualizan los remedios; los clasifican por síndromes, signos o síntomas para facilitar su uso y comprensión para los profanos (Perdiguero, 1990: cap. VI). Las primeras, en cambio (en la medida en que aparecen como etnografías holísticas), se proponen responder a cuestiones generales y no a enfermedades particulares. Las topografias, se dirigen a médicos y políticos, los recetarios y obras de divulgación a la población general. Las primeras no suelen publicarse, las segundas se reeditan profusamente.

Desde el siglo XVI y hasta el XIX, la medicina emplea los dos modelos de etnografía: una, la topografía, en que la noción de error vulgar tiene una funcionalidad explicativa en la medida en que nos habla de los obstáculos de las creencias al desarrollo de la prevención; y otra, recetarios o libros de divulgación, en los que la mezcla hábil de remedios empíricos y de remedios académicos permite que penetren en un tejido social en el que el número de médicos es escaso. La topografía apuntala el papel político y orgánico de la medicina; el recetario contribuye a legitimar su saber y su imagen social. Pero en ambos no se aprecian límites radicales entre saberes populares y cultos, sino amplias zonas de compromiso que se explican por la funcionalidad que adquieren en sus contextos culturales.

Los conceptos decimonónicos de folk-medicina y medicina popular ${ }^{6}$ son intentos de delimitación de un campo en un contexto en que las topografías (etnografías holísticas) están en crisis tras el fiasco de la teoría miasmática en manos del pastorianismo. Además, con la hegemonía del modelo médico de corte biológico, la medicina abandona el estudio de las dimensiones sociales y culturales como instancias explicativas de la etiología de las enfermedades. En ese contexto, y tras la progresiva medicalización de las ciudades europeas que sigue alentando la venta de

${ }^{6}$ Erwin Ackercknetch distinguió más tarde (1984: 7-8) entre medicina primitiva, etnomedicina y folk-medicina. El primer concepto remitía a las sociedades aborígenes; etnomedicina sería una concesión política de los antropólogos en los años cincuenta y folk-medicina (medicina popular o tradicional) debería reservarse a los modelos sincréticos de medicina en las sociedades históricas y se compondría de una mezcla articulada de medicina primitiva, galenismo y tecnología médica. Utilizaremos medicina popular, tradicional o folkmedicina como sinónimos, para las sociedades campesinas europeas o de América Latina; medicina primitiva, lo reservaremos para los sistemas médicos aborígenes. Consideramos como folklore médico a la etnografía de la medicina popular hecha por médicos, y etnomedicina a las investigaciones realizadas por antropólogos. 
prospectos y libros de divulgación, el campo permanece como un espacio poco medicalizado y lleno de survivals. Black trató de sistematizarlo en 1881 mediante el concepto de folk-medicine que incluye:

los hechizos, encantos, hábitos y costumbres tradicionales referentes a la conservación de la salud y la curación de las enfermedades, usados hoy y en tiempos pasados (1982: XI).

No le interesaba la medicina popular en sí, sino poner a prueba las tesis spencerianas sobre el psiquismo primitivo, puesto que:

hay cientos, millares de hombres (...) cuya incapacidad intelectual (...) no puede ser descubierta por sus hábitos, por sus formas habituales de vida sino por sus supersticiones y sus hechizos (Black, 1982: 290).

En consecuencia, para él:

Construir aisladamente la teoría de la folk-medicine es imposible, porque ésta se ha formado de muy variados y distintos materiales; pero quizás no sea una vana ilusión el esperar que en el estudio de los hechos coleccionados y clasificados se encuentre alguna ilustración para la historia intelectual del hombre (ibid.: 294).

No se propone tampoco elaborar una teoría al respecto sino aprovechar, ordenándolos, datos dispersos (algunos de primera mano) sobre prácticas de salud en los campesinos escoceses que:

están en la civilización pero no son de ella (...) son representantes y tipos únicamente de su clase en la sociedad moderna (...) en tanto su situación mental no dependa de hábitos impuestos por circunstancias exteriores, se hallan fuera del círculo de ideas modernas (ibid.: 288).

El interés de Black por la medicina es instrumental. Le sirve para rechazar las ideas de Spencer sobre el origen onírico o epiléptico de las enfermedades, y para relacionar su origen con la magia y la religión y, en última instancia, articular el pensamiento religioso y el natural anticipándose así a una extensa literatura antropológica posterior. El carácter especulativo de su obra impide considerarla como un intento de codificar y ni siquiera de teorizar sobre la medicina popular.

Ese papel debe reservarse a Giuseppe Pitré, que aprovechó su experiencia como médico rural y su formación como folklorista para elaborar una monografía y cuestionarios que sirvieron de modelo a varias generaciones de folkloristas. Estuvo muy influido por Lombroso que se había interesado por las relaciones entre las supersticiones populares y la delin- 
cuencia y, también, por Mantegazza cuya influencia se proyectaría en una interpretación psicologista del tema distinta de la propuesta por Tylor y Black. Pero su aportación fundamental consiste en haber elaborado el concepto de medicina popular y haberle dado el armazón teórico y epistemológico de la clínica positivista de la segunda mitad del xIX tal y como establece en el espléndido prólogo a su Medicina Popolari Siciliana.

Pitré fundamenta su etnografía en dos principios; el primero, que sólo un médico puede entender la medicina:

pero será malévolo, a mi juicio, el hacerse con la práctica y la creencia médica por aquel que no sea médico (...) Y la razón es ésta: que en el orden de la medicina es difícil al no médico el distinguir entre aquello que se considera como prejuicio y aquello que es ciencia (1896: VII)

El segundo que, frente al desorden de los repertorios anteriores sobre supersticiones, es necesario un criterio heurístico que no puede ser otro que el de la ciencia positiva:

sin una clasificación ordenada no se puede concebir una investigación buena para el folklorista y menos para un médico, el cual - nadie lo disimula - no debe despreciar lo que encuentra en las familia populares, fruto de experiencia por tanto lleno de prejuicios (ibid.: IX).

Para lo cual cuenta con una sensibilidad etnográfica que emerge de un largo peregrinar a la cabecera de sus enfermos:

Por esto estimo que mis treinta años de ejercicio médico han servido para algo y me han puesto en la situación ventajosa de saber que piensa, que hace el vulgo en las enfermedades que lo afectan y de que debe considerarse como de importación reciente de la informe masa de hechos que constituyen el patrimonio médico de las familias. (...) Mis primeros apuntes se iniciaron en 1870 , y no hubo día sin recoger algún dato, opinión, remedio, etc... (ibid.: VIII).

Su metodología positivista, seguida más tarde por muchos folkloristas médicos ${ }^{7}$, incorpora dos técnicas etnográficas específicas: la observación directa combinada con la anamnesis en la cabecera del enfermo (por tanto en el locus de la enfermedad), y un prolongado itinerario de campo basado en una casuística que se mide por décadas, que se presenta como el elemento fundamental de la fiabilidad de sus informaciones y que

' Víctor Lis reivindica también su tarea callada y que durante décadas le permite acumular las cuartillas de información (1949: 21). Toma para ello inspiración de Jesús Rodríguez López (1971) que ya en 1895 había sistematizado materiales sobre supersticiones. 
conduce, en la medida en que se realiza en un área geográfica y cultural muy bien delimitada, a la construcción de una etnografía médica específicamente siciliana ${ }^{8}$. Ahora bien, como no hablamos de antropólogos (que eran entonces más bien proclives a síntesis teóricas o compilaciones) el punto de referencia etnográfico de los médicos rurales no podía ser otro que la clínica, que se revela como una especie de etnografía. He aquí un buen ejemplo de finezza clínico-etnográfica:

De los hechos patológicos o fisiológicos doy siempre el nombre dialectal siciliano o especial de las islas. Lo ilustro con palabras, proverbios, fórmulas y con cuanto concurra a aclarar el pensamiento del pueblo en relación a los hechos. Nada es superfluo y nada es descuidado. Una frase incluso sin sentido es un documento vivo de un uso. La frase misma es el recuerdo mismo, reliquia de una vida física y moral de la que nace y en la que participó. Estas frases son de apariencia modesta, a veces demasiado modestas, pero cuántas de ellas pueden hacer nacer las ocasiones de la esperanza o reflejar las pasiones de la vida (Pitré, 1896: XIII-XIV).

El armazón teórico de Pitré no se limita a la codificación de las técnicas etnográficas, sino que da un paso más:

Los recolectores del folklore médico en Italia han sido pocos y se han limitado a recoger remedios comunes a algunas enfermedades comunes. La terapéutica ha sido siempre la preferida y de esa la Materia Médica (la farmacologia). Pero ninguno pensó que la terapéutica es una parte de la patología, como ésta lo es de la Medicina. El remedio reclama a la enfermedad, y ésta reclama a la salud, la cual representa el estado normal, las condiciones fisiológicas (ibid.: VIII).

A partir de aquí divide la medicina popular siciliana en cinco partes. Una primera que corresponde a los ejercientes de las artes de la salud en Sicilia: del especialista licenciado al "ciurmadore", del médico-cirujano al

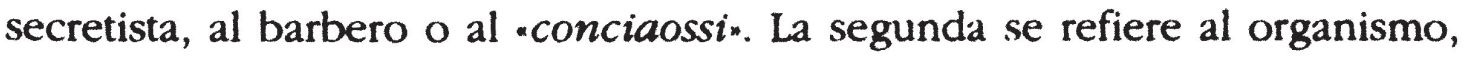
a la anatomía, criterios morales, caracteres y signos especiales, fisiología e higiene. La tercera a las observaciones sobre la naturaleza y las causas de las enfermedades, a los expedientes para conocerla y juzgar la duración

${ }^{8}$ Pitré puede compararse con los etnógrafos norteamericanos de la segunda mitad del XIX, como Cushing, Fewkes o Bourke, que compensan su falta de formación específica con un trabajo de observación sistemática y de clasificación con larguísimas estancias de campo, a menudo de más de cinco años. Bourke permaneció veinte años en el American Southwest (Porter, 1986). Vale la pena reseñar que la antropología británica -descubre. el estudio intensivo de casos en la primera década del siglo $\mathrm{xx}$ (Stocking, 1983; Hinsley, 1983), aunque no recupere la experiencia etnográfica de los norteamericanos ni la de Pitré. 
y el éxito, bueno o cautivo, próximo o lejano, para curarle (patología general). Finalmente, en las dos últimas incluye los males más importantes, sobrenaturales, o espontáneos, artificiales o adquiridos. Pero es consciente de que esta clasificación no está exenta de problemas:

La conveniencia de algunos epígrafes parecerá discutible a los médicos y a los no médicos, a unos porque, guardando algunas apariencias presumirán encontrarse frente a doctrinas científicas tratadas de forma más modesta; otros porque imaginarán elevado al lenguaje y rigor científico. Pero todo ese material no puede ir desordenado, y para clasificarlo no puede prescindirse de los criterios de los tratadistas (...). El problema es que a menudo no es posible distinguir, en los términos de una mujeruca, la anatomía de la fisiología y de la fisiognomía, ni es posible distinguir las delimitaciones de ésta de las de aquélla. Las cosas más disparatadas para nosotros se aproximan para el vulgo de un modo extraño y forman a nuestros ojos una amalgama oscura e irreconocible. Luego, cómo comparar los pronósticos, los presagios, las adivinaciones, y los juicios que se traen de un órgano dado al mismo órgano. Estas clasificaciones no existen en la naturale$\mathrm{za}$, las hacemos nosotros (ibid.: XI).

Por tanto, la tarea etnográfica no la concibe Pitré exclusivamente desde una perspectiva etic:

Un punto controvertido es el modo como clasificar las enfermedades. Hay dos procedimientos: uno por regiones del cuerpo, el otro por la naturaleza de la enfermedad. Ambos están actualmente llenos de defectos. El primero plantea problemas en enfermedades de las que desconocemos la patogénesis; la teoría patogenética ha introducido desorden en la patología topográfica. Por las segundas, los descubrimientos recientes cuestionan las clasificaciones. Si esto es válido para los científicos no lo es menos para el vulgo ( $i$ bid.: XII).

Esto explica que a menudo las clasificaciones que debe construir puedan entrar en aparente contradicción con las que propugnaría la medicina académica, pero sin que se plantee realmente una indagación sobre la lógica cultural de tales prácticas. Pitré, de hecho, sitúa a la medicina popular como:

Un conjunto compuesto por hechos curiosos y diversos, que en su totalidad aparecen como una aberración del espíritu humano, y que en particular son reliquias de la civilización y de pueblos desaparecidos (ibid.: XXII).

en el que encuentra, como Black, reminiscencias y sincretismos que vienen de la noche de los tiempos, pero en los cuales se halla un fondo de verdad que no debe ser simplemente despreciado y que Pitré reivindica?:

${ }^{9}$ La polémica está en Black (1982: 316 y ss). Machado y Álvarez pidió a los médicos Rubio y Galí y Olavarría información sobre medicina popular en España. Su corres- 
La importancia étnica y demopsicológica (folklórica) de las tradiciones médicas populares es indiscutible; pero a la vez hemos de recordar su importancia para la historia de la terapéutica: aquella de los remedios que conserva y que pueden tener carácter científico (...) Las creencias y las prácticas vulgares, no han de dispersarse sólo porque son de gente inculta. Su empirismo ofrece a veces resultados felices cuando fracasa a veces la medicina científica (...) Y cuántas veces, renunciando a medios racionales hemos tenido que observar el maravilloso efecto de ciertos remedios en mujerucas que no estaban anotados en ningún tratado de terapéutica (Pitré, 1896: XXIII-XXV).

Esta actitud empática no debe ser tomada acríticamente. Forma parte de una tradición que hemos vinculado a los libros de divulgación y a los recetarios. Pero eso no obsta para que el conjunto de las prácticas descritas sean situadas fuera de los límites de la ortodoxia médica, con lo cual, los etnógrafos, recuperando saberes populares, establecen las fronteras de su propio saber al construir un pattern cultural específico y distinto de la patología universal de la medicina. Las incongruencias que señalaba Pitré entre las clasificaciones científicas y las populares son las que sitúan a estas últimas fuera del sistema y por tanto tienden a distinguir lo que es, de lo que no es, algo que ya la religión había explicitado al hablar de la magia tras el Concilio de Trento. Dirá Rodríguez López en 1895 (1971: 14):

Este librito no tiene otro objeto que coleccionar las supersticiones para que el día de mañana sirvan de curiosidad histórica. A la par me propongo hacer ver a los engañadores, echadoras de carta, curanderos, etc., que conocemos esas prácticas y esas oraciones que ellos ocultan tanto y en cuyo misterio fundan la virtud que les atribuyen para favorecer su engañosa industria.

Y Amades (1980: 930) remachará:

El presente capítulo tiene espíritu científico y pensamos difícil que vaya a parar a manos de personas sencillas que hagan uso de las prácticas que contiene; pero, con todo, sentimos escrúpulos de dar aquellas fórmulas, el uso de las cuales puede perjudicar realmente a la persona a la que van dirigidas.

Aunque un análisis del folklore médico que lo contextualice adecuadamente está por hacer, apuntaremos algunos rasgos generales. La mayor parte de autores deslindan las "prácticas empíricas" de las mágicas, y

pondencia evidencia intereses distintos. Para Machado, este campo era uno más en la institucionalización del folklore, pero en los médicos hay curiosidad por las supercherías. y la idea de que en ellas había prácticas empíricas recuperables en las que sse suele encontrar un fondo de verdad que deja atónito. El texto de Olavarría había sido publicado en 1885 por el propio Pitré. 
describen las primeras como una combinación de técnicas eficaces y de prácticas inútiles, tendiendo a sobrerrepresentar los aspectos más vinculados a la magia y al papel de los curadores no empíricos. Como se evidencia en los cuestionarios de la sociedad El Folk-lore Español:

Medicinas: medicinas caseras y medicinas supersticiosas para el hombre y para los animales.-Ensalmos, conjuros y recetas contra la rabia, el mal de ojo y el embrujamiento.-Plantas, piedras y agua maravillosas para la cura de ciertas enfermedades. (...) La Luna: influencia de este astro en las enfermedades. El color y los números 3 y 7 en medicina ${ }^{10}$.

Aunque hay cuestionarios posteriores algo más sofisticados, tratan de investigar cuanto se halle en las antípodas de la medicina científica: magia, hechicería, brujería, superstición, endemoniamiento, astrología, que se asocian a la falta de educación, a la transmisión oral de conocimientos, al analfabetismo, al fanatismo, al atraso y al aislamiento o, desde otras perspectivas, al infantilismo de los no civilizados (Black, 1982: 278 y ss.). Se destaca su arbitrariedad fruto de la transmisión oral, o del uso de libros (como el Ciprianillo) en los que se rastrean ideas y teorías de las medicinas antiguas o las creencias paganas. Aunque se constate su sincretismo, los folkloristas componen un falso modelo evolutivo y los distintos autores se refieren a ellas como creencias estables que actúan como obstáculos a la penetración de la Medicina. Pero en cambio no hacen referencia al constante tránsito de enfermos de un modo de práctica al otro, ni explican la razón de tan extraño proceder y mucho menos tratan de relacionar la creencia en la mediación de curadores iniciados con la existencia de una teoría de la Iglesia en relación a la curación de enfermedades.

La articulación entre sistemas es precisamente la que les permitió a los folkloristas médicos efectuar sus investigaciones, pero entrar en ese debate representaba no sólo jerarquizar los modelos de práctica sino plantear consideraciones sobre el discurso curador de la religión (y no solo de la popular). Por ello, los esfuerzos de los folkloristas por distinguir la medicina popular de la culta se sitúan en un contexto de confrontación entre la ciencia positiva y las fuerzas de la irracionalidad.

La intelectualidad positivista veía la medicina popular bajo el prisma

${ }^{10}$ El Folk-lore Frexnense y Bético-extremeño (Badajoz: Diputación Provincial. Ed. facsímil, 1987, p. 339 [1883-1884]). Fueron redactados probablemente por Olavarría, que formaba parte de la sociedad. Los de Asturias son idénticos (ibid., 365). Hubo otros, como la Encuesta del Ateneo de Madrid de 1901-1902 (Lisón, 1971: 160-171), o los del Arxiu d'Etnografia $i$ Folklore de Catalunya (Calvo, 1990). El primero no distingue un campo específico en medicina popular, y el segundo, redactado por Vidal y Pujol, enfatiza más la anatomía que la medicina. 
de la ciencia racionalista y proyectaba sobre las prácticas populares un aparato conceptual cuya validez universal aceptaba sin cuestionar ni su epistemología, ni el contexto cultural de su construcción. Por eso su etnografía remite a la clínica, y es individualizada y particularizada y no una metodología que articule dinámicamente las variables como hacían los neohipocráticos. Al individualismo universalizador de la medicina opone la imagen del patrón cultural particular, a su a-socialidad biologizante, el discurso sobre la causalidad cultural mágico-religiosa de la enfermedad, frente a su mercantilismo presentan una medicina popular "más pura", que no implica remuneración - y si la tiene es superchería o charlatanismo (Amades, 1980: 930)-, y finalmente, frente a la falsa imagen de eficacia pragmática, la mágico-popular se presenta como ineficaz. Por este camino, no sólo los folkloristas están construyendo límites culturales a la patología académica, dejando fuera los síndromes delimitados culturalmente ${ }^{11}$, sino que, simultáneamente, están construyendo los límites empírico-positivistas del modelo médico hegemónico, estableciendo quién sabe y quién no sabe, qué saber es el verdadero y cuál es el falso, en dónde está la creencia irracional y en dónde el conocimiento científico.

La retórica y el estilo narrativo del folklore médico pone de manifiesto sesgos de clase y educacionales. Aceptan la universalidad de la ciencia moderna y ello conduce a un estilo narrativo que refuerza el particularismo o localismo de la medicina popular. Si los tratados de patología describen las enfermedades por sus formas clínicas, los de medicina popular lo hacen según las variantes locales del tratamiento o del diagnóstico. Muchos folkloristas médicos aprovechan el estilo de los tratados de medicina para ordenar sus datos - como Lis-, pero recurren al estilo del folklore para listar las variantes locales de las costumbres. Si el uso de este último es útil para la literatura oral o las recetas de cocina, en medicina refuerza la imagen de inconsistencia e irracionalidad a que aludíamos.

La patología médica fija mediante el razonamiento inductivo modelos de enfermedad; la popular los describe como mosaicos de casos sin llegar a síntesis. Hacerlo implicaría tratar de desentrañar su lógica oculta, lo cual estaría en contradicción con la asunción de irracionalidad que preside la

${ }^{11}$ Sobre síndromes de delimitación cultural como chisara-chisara, zuwadanda, empacho, susto, aire, agua, pasmo, bilis, ataque de nervios, celos, mal de pelea, latido, cólera, koro, amok, gila merian, gila talak, gila kena hantu, otak miring, latab, bah-tsi, dhat, shen-k'uei, qissaatuq, pibloktog, quajimaillituq, pa-feng, pa-leng, boxt, witiko, inarum, kiesu, giri, bwabyung, wool-bwa-byung, budub kedewandewan, dindirin, djukat, afota, abisinwin, aiyiperi, were agba, were alaso, tuyo, wacinko, tabacazo, shinbyung, tripa ida, ruden rupan, zar, womtia o espanto, entre los cientos posibles, ver Simons y Hughes (1985). 
retórica del folklore médico. Su estilo narrativo lo aproxima al folklore como colección de curiosidades en la que la variabilidad procede de la arbitrariedad y de la imprecisión de la transmisión oral o de fenómenos de difusión cultural. La vinculación entre ambos contribuye a distanciarlo del discurso dominante en medicina, a presentarlo como un camino obsoleto, y así a reforzar la confianza subjetiva de los médicos en su propia práctica.

\section{LA REINVENCIÓN ANTROPOLÓGICA DE LA MEDICINA POPULAR}

Una de las consecuencias de la escisión entre antropología y medicina (que se sustancia entre 1880 y 1920) fue el hecho de que folkloristas médicos europeos y antropólogos siguieran caminos divergentes. La medicina no se interesaba por lo social/cultural, y las escuelas antropológicas anti-evolucionistas dejaron de interesarse por la medicina ${ }^{12}$. Rivers fue la excepción. Se preocupó por la medicina y sus relaciones con la magia y la religión y dotó a la medicina aborigen del carácter de institución social en la que distinguía una concepción naturalista y empírica, una mágica y una religiosa (Rivers, 1924). Su esquema comparativo fue recogido en parte por Clements (1932), pero no repercutió ni en la antropología británica ni en la francesa anteriores a 1939. Éstas, y pese a que la enfermedad es referencia ineludible en sus estudios sobre brujería, hechicería, magia y religión, se interesan por la funcionalidad de la enfermedad en el control social y político y no por la eficacia biológica o psicoterapéutica que podía interesar a médicos y psiquiatras ${ }^{13}$.

Los antropólogos, cuyo proceso de profesionalización les condujo a primeros de siglo a centrarse casi exclusivamente en las sociedades aborígenes y algo más tarde en el campesinado, desarrollaron dos conceptos a partir de los años cuarenta, el de folk-medicine por Redfield y el de medicina primitiva por Ackercknecht.

${ }^{12}$ No sucedió lo mismo con los etnógrafos, que publicaron algunas monografías y artículos sobre las terapéuticas, y los medicine-men aborígenes norteamericanos y los chamanes asiáticos, como W. Matthews (1888), J. G. Bourke (1892), F. Russell (1898), o A. B. Reagan (1922). Aunque influidos por el evolucionismo, son menos especulativos e insinúan las posibilidades de aplicación del conocimiento etnográfico a programas de aculturación de los grupos aborígenes. Su interés por los sanadores indígenas viene sobre todo de su papel en la reproducción social.

${ }^{13}$ Por el lado médico-clínico, el interés por los aspectos psicopatológicos de los estados de trance o de conductas chamánicas era comparativo y transcultural. Eran desafios a la universalidad de los patrones científicos u ofrecían perspectivas inéditas sobre los mismos. 
Redfield, a partir de sus investigaciones entre el campesinado yucateco en los años veinte-treinta, propuso el concepto de sociedad folk que implicaba recuperar la noción de folk-medicine (Redfield, 1944). En su trabajo de campo los datos etnomédicos tuvieron un interés meramente tangencial, pero sus aportaciones conformaron buena parte de las investigaciones posteriores sobre los procesos de transición y aculturación de los sistemas médicos en las sociedades tradicionales y establecieron su papel como instrumentos de control social ${ }^{14}$. El concepto de folk-medicine era ya entonces una noción médico-céntrica ya que tendía a disociar la biomedicina de los sistemas médicos indígenas creando un sector alternativo "tradicional", de base sincrética, y que adquiría entidad propia y autonomía (Menéndez, 1981: 310). Su carácter sincrético se oponía a la idea de independencia de los sistemas médicos en tanto que lógicamente integrados en una configuración cultural determinada que caracterizaría, según Ackercknetch, la medicina primitiva. Hasta Redfield los antropólogos no habían utilizado de manera sistemática ningún término para definir ni las prácticas aborígenes ni las tradicionales sincréticas. La hegemonía de la idea evolucionista de que en las cosmovisiones nativas estaban fuertemente relacionadas la medicina, la magia y la religión, estructurando un sistema en nada comparable a la biomedicina, explica esa ausencia y que el término medicina primitiva no fuese acunado anteriormente.

El discurso de Ackercknecht contenía contradicciones fruto de su ambivalencia entre las posiciones universalistas y particularistas. Asumía una medicina primitiva articulada con la magia como ya habían indicado Tylor y Frazer; pero refutaba las teorías evolucionistas que la entendían como un precedente de la biomedicina. Para él, la medicina aborigen era, siguiendo a Benedict, parte de un "modelo cultural total" (Ackercknecht, 1984). Esta ambivalencia se explica por las influencias teóricas del funcionalismo, adquirido con Mauss en Francia, y de su formación médica en Leipzig con Sigerist en historia y medicina social. Estas influencias se entreven en sus escritos como una tensión entre universalismo y particularismo como indica su propio aparato conceptual: autornormal y autopatológico y beteronormal y beteropatológico ${ }^{15}$. Su obra adquirió valor,

${ }^{14}$ Estudió la transición entre el significado social de los sistemas médicos nativos de las aldeas a la sociedad urbana yucateca y observó que, junto al proceso de urbanización, aparecía una secularización progresiva de las prácticas terapéuticas asociadas a cambios en la división sexual de las funciones terapéuticas. El poder de curar se identificaba con el prestigio y esto propiciaba que en la sociedad tradicional los curadores fuesen fundamentalmente varones, mientras que en la ciudad -debido a la irrupción del modelo médico- proliferasen las sanadoras.

${ }^{15}$ Los primeros sirven para determinar la comprensión y catalogación que desde 
más que por sus teorías, por su rigor comparativo y compilativo sobre la terapéutica nativa. Junto con Redfield fue, sin duda, uno de los puntos de referencia de la etnomedicina durante más de dos décadas.

El problema de los funcionalistas era que asumir empíricamente la existencia del sincretismo entre sistemas médicos no permitía discutir sus raíces históricas y económico-políticas puesto que esto les hubiese conducido a una revisión de algunos postulados evolucionistas o marxistas ${ }^{16}$. Para huir de ello su única alternativa era reforzar la etnografía y el discurso sincrónico sobre el prestigio, el control social y la búsqueda del equilibrio social que resolvía implícitamente los límites del modelo positivista de la medicina popular de Pitré y de los folkloristas médicos. Éstos construían taxonomías que definían un patrón cultural de raíces étnicas o geográficas derivadas de la insularidad de Sicilia o de las clasificaciones étnicas de la Volkerpsychologie. De forma no muy diferente, el modelo de Ackercknetch enfatizaba, aunque con bases teóricas más sólidas que el simple empirismo, la dicotomía entre medicina culta y medicina popular y además por el flanco más débil de esta última: en el terreno de la falta de racionalización de su discurso.

La nueva medicina popular que se construye a partir de los esquemas de la medicina primitiva disocia las prácticas mágicas de las empíricas, deja en manos de la culta la biología y la eficacia biológica, y de la popular el simbolismo, la eficacia simbólica y en general lo social/cultural. A partir de aquí, en la medida en que los antropólogos apuntalan desde sus límites al modelo médico, pueden apropiarse de una parcela de saber que a los médicos ya no les interesa en Europa, puesto que el proceso de medicalización se ha consolidado, pero que en cambio conserva cierto valor en las sociedades del Tercer Mundo sometidas al proceso de medicalización.

La diferencia entre Pitré, por un lado, y Redfield y Ackerneckecht, por otro, es la oposición entre el empirismo clínico-positivista y meramente descriptivo del primero y las posturas holísticas sostenidas por los segundos. En cierta manera, los antropólogos funcionalistas hacen suyo el viejo

dentro del contexto cultural se efectúa de un fenómeno o conducta determinado y, por tanto, asumen el relativismo. Los segundos definen la interpretación que desde el punto de vista occidental puede hacerse de esos mismos fenómenos y por tanto adoptan un enfoque reduccionista y universalizador.

16 (Menéndez, 1981: 334). El propio folklore médico europeo evidenciaba que el sincretismo no era una condición suficiente para desarrollar un análisis dialéctico sobre su génesis, sino que podía reconducirse al terreno de ese falso evolucionismo característico de la historia natural en el que se postula la anterioridad o la posterioridad a través de comparaciones formales (Foucault, 1988: 151 y ss.). 
holismo de los neohipocráticos desproveyéndole del determinismo ecoambiental y mecanicista y sustituyéndolo por un particularismo cultural, pero en un contexto histórico en que la hegemonía del modelo médico se hace precisamente a partir del cuestionamiento del viejo holismo neohipocrático y del arrumbamiento a la condición de subalternos de modelos que le eran herederos como la homeopatía y el naturismo médicos.

El holismo antropológico se asienta, ciertamente, en otras bases más refinadas que las de los folkloristas médicos. Destaca su lógica y su funcionalidad social, y permite explicar las claves simbólicas de su eficacia y la relación de esta eficacia con el control y el equilibrio sociales, con la disminución de la ansiedad individual y colectiva y con su papel integrador de la comunidad. De ahí su énfasis en las dimensiones simbólicas y psicosomáticas frente a las puramente biológicas, en lo colectivo frente a lo individual, en su desmarque de la eficacia pragmática, en su falta de mercantilismo y en su contextualización social, cultural y comunitaria pero no individual. Un modelo cuyas notas características son no por casualidad las inversas a las que configuran el modelo médico (Menéndez, 1981: 494-504).

La antropología, de modo poco crítico, no quiso asumir que su discurso asentaba teóricamente, no los límites culturales de la medicina popular, sino los del modelo médico. En su faceta más relativista, presentó teóricamente, aunque de forma tímida, a la biomedicina como un sistema médico más; resolviendo, en apariencia, la dicotomía brutal entre la biomedicina y la medicina popular. También, ocultó en la práctica que, aunque los antropólogos construyesen esa práctica en torno a la noción de sistema médico, nunca consideraron a la biomedicina como un objeto más de estudio, puesto que estaban utilizando categorías y prioridades de la biomedicina para estructurar las medicinas primitivas, sin osar recorrer el camino inverso. El mismo proceder que había utilizado Pitré desde la medicina. Al estudiar las medicinas aborígenes médico-céntricamente, tendieron a interesarse por aquello que no interesaba a los médicos; esto es, el papel de la sociedad y la cultura en el proceso salud/enfermedad/ atención, y los discursos de los que la medicina consideraba legos y sobre los que seguía postulando la ignorancia y la inanidad ${ }^{1}$. Al apropiarse del

17 En las investigaciones posteriores etnomédicas se prioriza en general a los curadores y las terapias rituales. M. E. Modena (1990) señala que de 272 textos publicados en México sobre salud, 126 lo eran sobre medicina popular y de éstos el 80 por 100 hacía referencia a curadores, mientras que sólo el 31 por 100 a pacientes ( 7 por 100 se hizo sobre zonas rurales). Compárese con la bibliografía sobre automedicación en países desarrollados. Se publican un centenar de obras entre artículos y libros frente a los miles de estudios sobre hospitales o personal sanitario. 
discurso de los legos, los antropólogos se interesaron mucho más por el discurso teórico de los mismos -es decir, por las relaciones entre magia, hechicería y religión-, que por la estructura de sus prácticas y por la paradoja que representaba que, a pesar de sus apolíneas descripciones sobre la eficacia reguladora de la ansiedad, los aborígenes tomaban aspirinas, se vacunaban, o recurrían al médico. Con la ocultación del sistema biomédico, era ciertamente imposible comprender la lógica de la articulación entre sistemas que era perceptible en los itinerarios terapéuticos de los pacientes. Es por ello que este tipo de investigaciones etnomédicas características de la década de los cincuenta y sesenta pensarán los sistemas médicos en términos de ideas y no de prácticas ${ }^{18}, \mathrm{y}$, es por ello también, que el discurso de los antropólogos (salvo en la intervención en Salud Pública en el Tercer Mundo o en su contribución al desarrollo de la teoría y práctica de la psiquiatría social) carecerá de interés práctico para la biomedicina.

DE LA MEDICINA FOLK A LA ANTROPOlOGÍA DE LA MEDICINA

En los sesenta la etnomedicina se configuró como el campo de análisis de los sistemas médicos ajenos a la biomedicina. Pero quien espere hallar en ella una coherencia interna simplemente se equivoca. De hecho, emergió como un gigantesco "cajón de sastre" que reunía trabajos aplicados, investigaciones académicas, y etnografías. Buena parte de esta tarea no revirtió en la delimitación de un objeto de estudio y de un corpus teórico-metodológico, sino que se empleó "la salud como una excusa para explorar otros mundos o para disponer de un acceso a un mercado de trabajo secundario que permitiese, indirectamente, explorarlos. Aún no se había producido la ruptura de esa demarcación tácita que se estructuraba en torno a un doble criterio: medicinas indigenas vs. biomedicina y enfermedades mentales vs. enfermedades orgánicas. Las primeras eran posibles objetos de análisis antropológico, las segundas delimitaban un terreno clínico, epidemiológico y biomédico. Además hay que tener en cuenta que

\footnotetext{
"* Marc Augé y Claudine Herzlich (1984) sugieren que esto es un artefacto derivado de la técnica de campo en sociedades lejanas, en las que es más fácil reconstruir los discursos que efectuar seguimientos sistemáticos a la cabecera del enfermo. Para un investigador ajeno es difícil acercarse a ella. Esto explica que las investigaciones en torno a prácticas e itinerarios individuales hayan sido desarrolladas en las sociedades occidentales y constituyan la principal aportación de la sociología a la antropología de la medicina.
} 
en ese momento la etnomedicina era un discurso subalterno tanto para la medicina como para la antropología.

No obstante, a partir de la década de los setenta las concepciones sobre la medicina popular o la primitiva se modificaron profundamente sobre la base de dos interrogantes: ¿cuál debía ser el lugar de la biomedicina en el contexto de los diferentes sistemas médicos? ¿Hasta qué punto podían considerarse la medicina popular o la medicina primitiva como fenómenos objetivamente diferenciados de los saberes y las prácticas científicas occidentales? La emergencia de estas cuestiones había sido el resultado del desarrollo de una antropología aplicada a la biomedicina durante los cincuenta y la constatación de sus insuficiencias teóricas en terrenos como las instituciones psiquiátricas o las campañas sanitarias en el Tercer Mundo. Pero la ruptura con la dicotomía medicina popular/ biomedicina no se producirá de forma rápida sino que constituirá, de hecho, uno de los rasgos distintivos de la primera antropología de la medicina. De ahí que Fabrega, uno de los precursores de esta especialidad, definiese inicialmente este campo de la siguiente manera:

(a) elicita los factores, mecanismos y procesos que juegan un papel en o influyen en la forma en que individuos y grupos están afectados por y responden a la illness y disease, y (b) examina estos problemas con un énfasis en patrones de conducta. El énfasis principal debe darse en estudios que son conducidos en grupos no-occidentales y que descansan en el concepto de cultura (Fabrega, 1972: 167).

La definición guarda la ambigüedad necesaria para congeniar las investigaciones desarrolladas tanto desde la salud pública como desde la antropología culturalista. Pero lo interesante es que mantiene la escisión entre el espacio antropológico y el biomédico, remitiendo el primero al universo indígena y distinguiendo entre dos dimensiones de la enfermedad, Disease (dimensión biológica) e Illness (dimensión cultural). Además, Fabrega propone, como Pitré, usar el paradigma biomédico como punto de referencia para organizar términos, metodologías y propuestas teóricas que se mueven entre los límites de lo orgánico y lo sociocultural, pero en el que la disease (el dominio de la biomedicina) tiene un papel hegemónico. El modelo conceptual de Fabrega enlaza aquí con la vieja identificación de lo folk con la antropología y de las dimensiones orgánicas con el discurso biomédico. Pero es también justo decir que, aunque su producción inicial está atrapada en el modelo médico, al proponer la enfermedad y sus dimensiones, y no la "medicina como el objeto de estudio de la antropología de la medicina, abre las puertas a una delimi- 
tación precisa del campo y adopta un concepto operativo para la investigación y la discusión teórica.

En una línea más marcadamente continuista que Fabrega, Foster unos años más tarde distingue entre dos tipos de sistemas médicos "no-occidentales*: los personalistas y los naturalistas. Describe los primeros como aquellos sistemas de concepciones característicos de las sociedades indígenas en donde las causas de la enfermedad son interpretadas en términos de agentes activos relacionados con personas y acciones morales ${ }^{19}$. Contrariamente, los sistemas naturalistas serían aquellos en donde la enfermedad es atribuida a una falta de equilibrio y su emergencia no es identificada con otras desgracias porque los procesos mágicos y religiosos no aparecen estrechamente vinculados a la enfermedad. Foster trata, en el fondo, de resolver el problema teórico que planteaban a los antropólogos las prácticas empíricas, pero su aportación fue fuertemente criticada por médico-céntrica. Simplemente había algo que llamaba la atención por su ausencia: la biomedicina.

La crítica no se hace esperar. Poco tiempo después, Kleinman, que representa a la vanguardia de la antropología de la medicina norteamericana, critica a Foster de forma contundente (Kleinman, 1978 y 1980). El modelo de Foster es una generalización comparativa poco fundamentada, indiferente a las prácticas terapéuticas y de escasa aplicación en contextos concretos. Pero, lo que es más importante, critica a Foster sobre todo por continuar con la demarcación tácita entre medicina popular y biomedicina. En su lugar, Kleinman aboga por una aproximación cultural centrada en la salud, la enfermedad y las prácticas que desafíe el paradigma biomédico con un grupo alternativo de conceptos y un foco analítico diferenciado. Kleinman asume la dualidad Disease/Illness que había desarrollado Fabrega pero con una nueva perspectiva. La disease no constituirá una realidad biológica en sí misma sino la interpretación que elaboran los profesionales de la biomedicina de una determinada enfermedad (su modelo explicativo). Y esta dimensión podrá constituir un objeto de estudio de la antropología de la medicina de la misma manera que las concepciones de los pacientes y sus familiares o illness. Aquí se esboza una distinción significativa con respecto a la diferenciación de Fabrega: el propio conocimiento biomédico, y no sólo la manera como afectan las varia-

\footnotetext{
19 La envidia puede traducirse, por ejemplo, en mal de ojo y éste causar enfermedades. Además, y siempre según Foster, en los sistemas personalistas la responsabilidad no se centraliza de forma exclusiva en el paciente, sino que se atribuye a instancias más periféricas. La religión y la magia aparecen profundamente imbricadas con las concepciones sobre la enfermedad y ésta es puesta en un mismo plano con las desgracias generales de la vida cotidiana (Foster, 1976: 781; Foster y Anderson, 1978: 57-80).
} 
bles socioculturales a las enfermedades, se revela como un objeto de estudio.

Su aproximación a los sistemas médicos, descansa en la adaptación del concepto de sistema cultural desarrollado por Geertz y que incluye a la biomedicina como un objeto posible. En una de sus más conocidas obras (Kleinman, 1980) profundiza en esta dirección formulando un modelo teórico no sólo para el análisis de los sistemas médicos, sino también para el de las diferentes transacciones y funciones-core clinical functions-, que se desarrollan en un contexto determinado. Utiliza para ello el concepto de bealth care system $^{20}$ que engloba el conjunto de sistemas de atención y gestión de la salud existentes en un marco cultural específico, ya sean sistemas folk o altamente profesionalizados $\mathrm{e}$ institucionalizados como el biomédico ${ }^{21}$. La medicina alopática, cosmopolita, occidental o biomedicina es un sistema cultural. Su configuración como objeto de estudio implica nuevas orientaciones teóricas para la antropología:

La biomedicina y los otros sistemas socioculturales reconstruyen de forma continua la naturaleza, incluyendo la naturaleza humana; pero la naturaleza constrine recíprocamente qué se puede hacer de ella. La biomedicina es así el producto de una dialéctica entre la cultura y la naturaleza. Haciendo de esta dialéctica un foco central la Antropología de la medicina confronta la teoría antropológica general con una problemática vital y ofrece un objeto para su exploración (Hahn y Kleinman, 1983: 306).

La dialéctica naturaleza-cultura adopta aquí una posición estratégica junto con dicotomías como mente-cuerpo o individuo-sociedad, y se apuntan nuevos temas a analizar en el marco de la medicina occidental como su sistema ideológico, división del trabajo en especialidades y jerarquías, normas de práctica e interacción, sistema de rol/estatus y procesos de socialización de los profesionales y de construcción y reconstrucción del conocimiento (Hahn y Kleinman, 1983: 311). Estas propuestas se

${ }^{2 n}$ Los antropólogos norteamericanos dejan en un segundo plano la noción de folkmedicine. El propio Kleinman, al distinguir entre un sector profesional (biomédico), otro folk (que se refiere esencialmente a curanderos) y un tercero popular (que incluye la automedicación y la autoatención), esquiva la cuestión mediante la noción de bealtb care system que se constituye como un concepto heurístico sobre el cual funda su metodología de investigación.

${ }^{21}$ Frente a Fabrega, que trata de delimitar una ciencia etnomédica, Kleinman es más pragmático, pero el HCS no deja de recordar los case studies de la antropología británica de los cincuenta. El HCS aparentemente sólo es perceptible por el investigador cuando se activa; es decir, en las situaciones de enfermedad que se constituyen verdaderamente como objeto de estudio de la antropología de la medicina. 
adaptan bien a los nuevos vientos de las ciencias sociales que tratan de capturar a la biomedicina como una subcultura (aunque médica) con sus propias reglas del juego, valores y prácticas. Ya no hay límites epistemológicos entre conocimiento y creencia, entre ciencia y medicinas populares a la hora de encarar una investigación etnográfica. La biomedicina es ahora una etnomedicina y la psiquiatría una etnopsiquiatría (Fabrega, 1990: 129). Hay, no obstante, territorios inexplorados desde el culturalismo de Kleinman: la dimensión histórica y política de los sistemas médicos.

\section{LA RECUPERACIÓN DE LA MEDICINA POPULAR}

Il circolo del discorso storiografico è stato in tal modo chiuso: dal presente al presente, mediante il passato e per illuminare il presente (De Martino, 1983: 345).

La única antropología que revisó precozmente la noción de medicina popular clínico-positivista fue la italiana. Pitré, al margen de teorizar sobre ella, la había situado en el marco del discurso político italiano, en el cual la persistencia de formas de comportamiento mágico, la religiosidad barroca, y las formas mágico populares de gestión de la salud en un contexto de pobreza, explotación y miseria, ponían en evidencia un modelo de práctica política y exigían una perspectiva analítica menos reduccionista y mecanicista que la del positivismo. De ahí que la necesidad de elaborar estrategias políticas nuevas en un contexto específico explique la revisión que hizo el marxismo italiano para conciliar su discurso sobre la clase obrera con el correspondiente al campesinado, así como para articular la diversidad cultural con la que se había de confrontar ${ }^{22}$.

La crítica de Gramsci, incorporada precozmente por la antropología italiana a través de De Martino, supuso una síntesis entre la militancia del antropólogo, su participación en la lucha por las desigualdades sociales y una revisión profunda de la significación histórica de los saberes populares en unos términos que ninguna otra antropología del Sur de Europa llegó a hacer ${ }^{23}$.

22 De ahí el interés de Gramsci por el folklore y por el papel del intelectual en la elaboración de los saberes. Sobre Gramsci y la antropología ver Eduardo Menéndez (1981: 386 y ss), en donde hace una revisión profunda de las nociones de hegemonía/ subalternidad con el objeto de demoler el modelo funcionalista de antropología médica y sentar las bases de un proyecto específico de análisis del proceso salud/enfermedad/ atención.

2.3 Probablemente porque otras antropologías carecían de un marco comparable de análisis de lo que eran las relaciones entre cultura popular y cultura de élites y porque 
La obra de De Martino se inserta en la discusión del problema de las clases subalternas en el Mezzogiorno, el mismo ámbito que interesó a Gramsci. Para De Martino esa cultura era un testimonio del riesgo generado por la explotación clasista y colonial. Se preguntaba, si esas clases eran capaces de establecer una alternativa frente al desarrollo capitalista, y encontró la respuesta en la magia.

En la medida en que el atraso económico y social aparece relacionado con formas de disgregación y disociación de la personalidad, con el hambre, la mortalidad infantil, la falta de recursos médicos y la persistencia de creencias populares mágicas, la psicopatología aparece como un recurso socialmente estructurado (y casi único) para resolver determinados conflictos personales para los cuales no existe otra opción. Es en el riesgo permanente ante la desgracia en donde se pierde la conciencia y, eventualmente, la vida; en donde se hallan los fundamentos de una clase subalterna que deshistoriza permanentemente la realidad a través del ritual mágico para conjurar el riesgo, aunque esto genere un proceso de dominación y explotación. La superación de las crisis pasa por deshistorizarlas, por constituir un conjunto de técnicas que tratan de proteger a los individuos y ofrecerles una oportunidad de operar con sentido realista. Y esto es lo que permite que, con independencia de la existencia de médicos o de instituciones, persistan esas conductas en situaciones de crisis.

De Martino criticó la reificación taxonomista y falsamente historicista de la magia practicada por etnólogos e historiadores (De Martino, 1983a: 219). Para él era un artefacto metodológico que inducía a renunciar a comprender su significado $\mathrm{y}$, de paso, a ocultar el papel de dominación que ejercía sobre las clases subalternas deshistorificándola, y convirtiéndola en supervivencias que se remitían a reminiscencias paganas ${ }^{24}$.

Estas relaciones implican una profunda revisión de la relación entre modelos macrosociales y microsociales, en la medida en que los primeros no son percibidos como una especie de superestructura desde la que se controla, como si de marionetas se tratase, a los individuos, sino que se

no disponían de un instrumento de contextualización de su práctica como el que emergía en un Estado como el italiano. El folklore positivista nunca ha sido revisado críticamente en España, puesto que se ha subordinado fundamentalmente al debate sobre las alternativas a la configuración del Estado: es decir, la tensión entre centro y periferia y el debate sobre la etnicidad (Comelles y Prat, 1992).

24 De Martino fundó su reflexión teórica en análisis etnográficos e históricos minuciosos sobre el lamento fúnebre lucano (1983), el mal de ojo y la fascinación (1983a) y el tarantismo (1968). En estas monografias ponía a prueba las relaciones entre modelos hegemónicos y subalternos, y muy especialmente sobre el papel de la Iglesia católica y del propio Estado. 
recupera plenamente la conciencia del ser, de la presencia individual, en un contexto en que vemos proyectarse la complejidad del mismo. Complejidad que se refleja en la articulación de praxis distintas situadas a niveles distintos (popular, médica, política, eclesiástica), y que se hallan entre ellas en una relación dialéctica con las creencias, los rituales y la simbología a las que remiten y a las que alimentan y de las que se alimentan.

La finura de análisis de la obra de De Martino emergía de un contexto muy particular, pero no menos que el de la emergencia del discurso estructural-funcional sobre la brujería primitiva. Pero si éste último adquirió el valor de "universalidad", el discurso de De Martino quedó confinado en la "marginalidad", en el "localismo", pese a que representaba, en el momento en que se formulaba, un brillantísimo análisis sobre la articulación entre lo tradicional y lo culto, entre lo escrito y lo transmitido oralmente. Pero De Martino no fue nunca entendido por la ciencia anglosajona, cuyos análisis sobre el catolicismo fustigó (De Martino, 1965: 224-225). Puso, frente a la pretensión de universalidad del funcionalismo, el compromiso político, frente a la sincronía, el enfoque histórico-cultural, valores y perspectivas ambos que eran cuestionados por la antropología hegemónica de mediados de siglo.

Su revisión crítica sobre la etnografía de su propio país representa un hecho de suma importancia para la antropología de la medicina en la medida en que sus aportaciones permiten resolver algunas cuestiones pendientes en relación al objeto de estudio, que la antropología anglosajona y francesa no habían sabido resolver. Sobre todo en lo que respecta a la articulación entre el modelo médico y los modelos subalternos de medicina popular, y la de ambos con los sucesivos modelos religiosos que emanan del cristianismo y sus transposiciones en las clases populares, no como una religiosidad popular escindida empíricamente de la religión oficial, sino como la interpenetración de ambos discursos.

La antropología de la medicina italiana heredera de De Martino ha elaborado una concepción operativa de la medicina popular consciente de lo que se halla en el lado opuesto. Su aportación fundamental es una teoría de las prácticas y una teoría sobre la articulación entre sistemas, que explica no sólo los sincretismos fruto del proceso de medicalización rural, sino también la elaboración de formas culturalmente específicas en las ciudades (Seppilli, 1984).

Gramsci y De Martino han influido en las antropologías latinoamericanas. Adquieren relevancia en contextos socio-políticos en los que la estructura social y la escisión entre la sociedad civil y las clases populares recuerdan al Mezzogiomo. Menéndez y sus colaboradores estudiaron bajo 
ese prisma los procesos de enfermedad y de atención de la salud en Yucatán (Menéndez, 1981). En él se articula de forma interdisciplinar el análisis médico, pero también histórico, estadístico y etnográfico de las condiciones de vida, de los servicios sanitarios y de los procesos de gestión de la salud en la población yucateca, en el mismo contexto que Redfield. Sus objetivos iniciales fueron vincular las dimensiones socioeconómicas con el desarrollo de la enfermedad en las zonas rurales, pero de la investigación emergen nuevas vías de exploración de problemas como la automedicación de las clases populares, los usos del alcohol y el desarrollo de prácticas médicas y paramédicas que adquieren su sentido en los vínculos entre lo particularmente regional, la penetración del modelo médico y las estructuras políticas y económicas. Pero esto no supone una asunción teórica de lo que él llama falsas dicotomías micromacro que han estado representadas por opciones ideológicas (culturalistas) y materialistas (marxistas) (Menéndez, 1981: 15).

Las aportaciones de la antropología italiana y de la mexicana, son probablemente el intento más completo para tratar de integrar las variables biomédicas, culturales y sociales en un marco comprehensivo en que se proyecten esas relaciones tanto en el plano de lo sincrónico como, sobre todo, en el diacrónico. La combinación de una perspectiva histórica de larga duración, y que se imbrica con el papel ideológico de la medicina y/o de la Iglesia, con relevamientos etnográficos de las formas culturales específicas, configura un tipo de aportaciones que aúnan lo académico, en el sentido estricto del término, con una peculiar capacidad didáctica en el sentido de poner de manifiesto, y de una manera global, las distintas piezas del puzzle en que consiste el problema estudiado. Frente al reduccionismo de enfoques como los de la antropología marxista francesa, la proyección histórica en la antropología italiana o en la mexicana devuelve a la realidad su complejidad, a los individuos su capacidad de comprender y de actuar. Se trata de una nueva dinámica menos mecanicista que abre sus planteamientos a un nuevo papel de la ideología que aquí es transformada en términos de una cultura popular. Y ésta no se recompone etnográficamente en términos de un epifenómeno de las formas duras de la vida material, sino que se sitúa en esa

sociedad de los hombres, de los hombres que se reúnen, se comprenden, desarrollan a través de esos contactos (cultura) una voluntad social, colectiva y entienden los hechos económicos, los juzgan y adaptan a su voluntad hasta que ésta se convierte en motor de la economía, en plasmadora de la realidad objetiva (Gramsci. cf. en Aguirre Beltrán, 1986).

El concepto de medicina popular sobrevive, pero a costa de una redefinición política de su contenido y del análisis histórico de su condi- 
ción de problemática ideológica, legitimadora y deslegitimadora, encubridora de estrategias de la biomedicina y de formas populares de resistencia no sólo ante los infortunios de la vida sino también ante la hegemonía de una ideología dominante.

\section{INTERROGANTES}

Hasta aquí hemos tratado de presentar cuatro redefiniciones de la noción de medicina popular. La primera surge como una necesidad de legitimación del modelo médico. La segunda representa la apropiación antropológica de un concepto que, mientras conscientemente permite definir un terreno de investigación, tácitamente salvaguarda la demarcación entre lo folk y lo científico, entre la creencia y el conocimiento. En un posterior avance hemos mostrado el surgimiento de la nueva antropología de la medicina como resultado de la no aceptación de esta demarcación y que fácilmente podemos resumir en la idea de que la biomedicina es también una etnomedicina. Finalmente, hemos dirigido la atención sobre una curiosa recuperación de la noción de medicina popular que, más que efectuarse a costa de la asunción de la separación popular-científico, hace precisamente de esta distancia epistemológica su propio objeto de estudio. Aquí ya no hay acuerdos tácitos sino planteamientos críticos. La separación epistémica se ha convertido en distancia social, económica y política que es ininteligible sin la conciencia de que ya no hay un objeto "exótico", sino dos polos que se ofrecen su sentido. En la construcción del discurso etnográfico tradicional sobre la medicina popular parece ser que uno haya sido representado por la mirada aséptica de un observador y el otro por la de un aparente "texto pasivo" e inmutable ante el observador y ante lo que él representa. Con ello se producía la ilusión de un objeto coherente para unos (funcionalistas) o incoherente para otros (folkloristas médicos) pero en definitiva aislado en el tiempo y en el espacio social.

Ante esta especie de proceso de redefinición, si no rectificación, conceptual cabe, también, preguntarse por la actitud del antropólogo ante las nuevas circunstancias. Un tema que ha dado pie a recientes y vistosos debates en una antropología norteamericana enfrentada entre una clinically applied antbropology, o antropología aplicada a la clínica, y una critical medical anthropolog $v$, o antropología crítica de la medicina ${ }^{25}$.

\footnotetext{
${ }^{25}$ Una síntesis sobre este debate en Comelles y Martínez Hernáez (1993). Los que deseen una aproximación directa pueden consultar Singer y Baer (1983); Singer, Baer y Lazarus (1990); Johnson y Sargent (1990), entre una larga lista de libros y artículos. Véanse principalmente las revistas Medical Antbropology Quarterly, Culture, Medicine and Psychiatry y Social Science and Medicine.
} 
Es, en definitiva, el conflicto entre, por un lado, plantearse como objetivo la intervención como analista de problemas sociosanitarios y como agente susceptible de intervenir en distintos niveles de la atención de salud con el objeto de aportar modificaciones estructurales o puntuales; y, por otro, elaborar un discurso independiente y crítico en donde ya no hay medicinas populares aisladas sino también procesos de producción y reproducción del modelo médico. Además, en el panorama intelectual queda otra opción posible, que no excluye a ninguna de las alternativas anteriores, como es el estudio de las dimensiones de la enfermedad y de la aflicción con objeto de desarrollar modelos conceptuales y propuestas teóricas - algo que el modelo médico no se propone en la actualidad-.

En cualquiera de estas tres alternativas que actualmente se barajan, o en otras posteriores que se propongan, el concepto de medicina popular podrá tomar un lugar en las nuevas teorías y modelos. Pero el problema es que ese lugar ya no podrá sostenerse como un territorio epistemológicamente aislado de otros dominios menos exóticos a nuestra mirada como un ambulatorio de la seguridad social, el hospital de una gran ciudad europea o las ideas y nociones de un grupo de afectados por el SIDA. Hay razones teóricas para ello, como es la respuesta a la pregunta ¿por qué unos sí y otros no constituyen un objeto de estudio? Pero también prácticas, como la dinámica cambiante de las culturas tradicionales y su progresiva afectación por lógicas ideológicas y socio-económicas tremendamente amplias. Por no profundizar en el universo constante de nuevas problemáticas, como el incremento exponencial del gasto sanitario, las reformas asistenciales en sectores como el psiquiátrico, las políticas sectoriales de educación para la salud, el crecimiento de las migraciones étnicas de países pobres a países ricos, la emergencia de determinadas tecnologías como las fecundaciones in vitro, las técnicas de mantenimiento artificial de la vida, o los problemas relativos a la eutanasia, al aborto, o al derecho a la contracepción. Toda una serie de temas que se sitúan en los límites entre la medicina, la biología, las ciencias jurídicas y las ciencias sociales y que tienen trascendencia en la configuración de una nueva ética, en la revisión de determinados presupuestos morales, pero sobre todo en la construcción de nuevas formas culturales que son las que van a engendrar un campo fascinante de estudio en los años venideros.

\author{
ÁNGel MARTÍNEZ Hernáez \\ JOSEP MARIA COMELLES \\ Dept. d'Antropologia Social i Filosofia \\ Universitat Rovira i Virgili \\ Tarragona
}




\section{BIBLIOGRAFIA}

ACKERCKNETCH, ERWIN, 1984: Medicina y Antropología social, Madrid: Akal. Aguirre Beltrún, Gonzalo, 1986: Antropología médica, México: CIESAS. AMADES, JOAN, 1980: El Folklore de Catalunya: costums $i$ creences, Barcelona: Ed. Selecta. Augé, Marc y Herzlich, Claudine, 1984: Le sens du mal, Paris: Eds. des Archives Contemporaines

BlaCK, W. GeORGE, 1982: Medicina Popular, Barcelona: Alta-Fulla [orig. 1883].

Bourke, J. G., 1892: The Medicine Men of the Apache. Ninth Annual Report of the Bureau of Etbnology, Glorieta. N. Mex: The Rio Grande Press.

Calvo, LUIs, 1990: Catàleg de materials etnogràfics del Arxiu d'Etnografia $i$ Folklore de Catalunya, Barcelona: CSIC.

CANGUilhem, GeORges, 1955: La formation du concept de réflexe aux xVIIf et XVIf siècles. Paris: PUF.

- 1989: Études d'bistoire et de philosophie des sciences, Paris: Librairie Philosophique J. Vrin.

Carrasco, Silvia, 1989: “Assaig de Reconstrucció d'un passat alimentario: Sabadell cap al canvi de segle, Arxiu d'Etnografia de Catalunya, 7, 113-136.

Castillo de lucas, ANTONio, 1952: "Concepto y contenido del folklore médico", Asclepio, 4, 249-257.

- 1952a: •Folklore y Terapéutica. Notas para un ensayo de Antropología cultural médica*, Asclepio, 4, 551-562.

Clements, FORREST E., 1932: :Primitive Concepts of Disease,, University of California Publications in American Archeology and Ethnology, 32-2, 185-252.

COMElles, Josep MARIA y MARTINEz HeRnÁEz, Ángel, 1993: Enfermedad, cultura y sociedad: un ensayo sobre las relaciones entre la antropologia y la medicina, Madrid: Eudema.

- y Prat, Joan, 1992: El estado de las antropologías. Antropologías, folclores y nacionalismos en el Estado español., Antropología, 3, 35-61.

De Martino, Eduardo. 1965: Magia y civilización, Buenos Aires: El Ateneo.

- 1968: Terre du remords, Paris: Gallimard.

- 1983: Morte e Pianto Rituale. Dal Lamento Funebre Antico al Pianto di Maria, Turin: Paolo Boringhieri.

- 1983a: Sud e magia, Milano: Feltrinelli.

ERKOREKA, ANTÓN, 1985: Análisis de la medicina popular vasca, Bilbao: Etniker-Labayru Ikasteguia.

FABREGA, HoRACio JR., 1972: ‘Medical Anthropology", Biennial Review of Antbropology, 167-229.

- 1990: *A Plea for a Broader Ethnomedicine-, Culture, Medicine and Psychiatry, 14, 129-132.

FOSTER, GEORGE M., 1976: •Disease Etiologies in Non-Western Medical Systemss, American Anthropologist, 78, 773-782.

- y ANDERson, B. G., 1978: Medical Antbropology, New York: John Wiley \& Sons Inc.

FOUCAUlT, Michel, 1988: Las palabras y las cosas, México: Siglo XXI.

GUICHOT Y SIERRA, ALEJANDRO, 1984: Noticia bistórica del folklore, Sevilla: Junta de Andalucía [orig. 1922]. 
Hahn, R. A., y Kleinman, A. M., 1983: Biomedical Practice and Anthropological Theory", Annual Review of Anthropologv, 12, 305-332.

HINSLEY, CURTIS, 1983: Ethnographic Charisma and Scientific Routine. Cushing and Fewkes in the American Southwest., en G. W. STOckING (comp.), Observers Observed, Madison: University of Winsconsin Press, 53-69.

Johnson, T., y SARGENT, C. (eds.), 1990: Medical Anthropology: Contemporary Theory and Method, New York: Praeger.

Kleinman, ArTHUR M., 1978: "What Kind of Model for the Anthropology of Medical Systems?:, American Anthropologist, 80, 661-665.

- 1980: Patients and Healers in the Context of Culture: An Exploration of the Borderland between Anthropology, Medicine, and Psychiatry, Berkeley: University of California Press.

LARREA, CRISTINA, 1994: Los miasmas. Antropología bistórica de un concepto médico, Barcelona: Universitat de Barcelona. Tesis de Doctorado.

LIS QUiBÉN, VÍCTOR, 1949: La medicina popular en Galicia, Pontevedra.

Lisón Tolosana, Carmelo, 1971: Antropología social en España, Madrid: Siglo XXI.

MATtHEWs, W., 1888: "The Prayer of a Navajo Shaman", American Anthropologist, 1, 139-192.

MENÉNDEZ, EduARDo, 1978: "El modelo médico y la salud de los trabajadores", en BASAGLIA et. ali., La Salud de los Trabajadores, México: Nueva Imagen, 11-53.

- 1981: Poder, estratificación y salud. Análisis de las condiciones sociales y económicas de la enfermedad en Yucatán, México: Eds. de la Casa Chata.

Modena, M. E., 1990: Madres, médicos y curanderos. Diferencia cultural e identidad ideológica, México: Eds. de la Casa Chata.

PERDIGUeRO, ENRIQUe, 1990: Los tratados de medicina doméstica en la España de la llustración, Alicante: Universitat d'Alacant. Tesis de Doctorado.

- 1992: "The Popularization of Medicine during Spanish Enlightment., en PORTER (comp.), The Popularization of Medicine 1650-1800, London: Routledge, 160-193.

PÉREZ VIDAL, JOSÉ, 1945: Contribución al estudio de la medicina popular canaria, La Laguna: CSIC.

PITRÉ, GIUSEPPE, 1896: Medicina Popolare Siciliane, Torino-Palermo: Biblioteca delle Tradizioni Popolari Siciliane.

- 1910: Medici, chirungi, barbieri e speziali antichi in Sicilia, secoli XIII-XVIII. Curiosità storiche e altri scritti, reed. Casa Editrice dell Libro Italiano, 1939.

PORTER, JOSEPH C., 1986: Paper Medicine Man. Jobn Gregory Bourke and bis American West, Norman, OK: University of Oklahoma Press.

Prats, LloRENÇ, 1990:- Aportaciones de las topografías médicas al conocimiento etnográfico de los Países Catalanes*, Boletín de Historia de la Antropología, 2, 3-7.

Reagan, A. B., 1922: "Medicine Songs of George Fermer", American Anthropologist, 24, 332-369.

REDFIELD, ROBERT, 1944: Yucatán: una cultura en transición, México: FCE.

RIVERS, W. H. R., 1924: Medicine, Magic and Religion, London: Kegan Paul.

RODRIGUEZ LOPEZ, JESÚs, 1971: Supersticiones en Galicia y preocupaciones vulgares, Lugo: Celta forig. 1895].

Russell, F., 1898: "An Apache Medicine Dance, American Antbropologist, 11, 367-372. SEPPILL, TUluo, 1984: -La medicina popolare in Italia., La Ricerca Folklorica, 8, 3-12. Simons, Ronald C. y Hughes, Charles C., 1985: The Culture-Bound Syndromes, Dordrecht: Reidel Publishing Co. 
SINGER, M. y BAER, H., 1983: -Why not have a Critical Medical Anthropology", Annual Meeting of the American Antbropological Association.

-; BAER, H. y LAZARUS, E., 1990: "Critical Medical Anthropology in Question", Social Science and Medicine, 30, V-VIII.

STOckING, G. W. JR., 1983: "The Ethographer's Magic: Fieldwork in British Anthropology from Tylor to Malinowski, en G. W. STOCKING (comp.), Observers Observed, Madison: University of Winsconsin Press: 70-120.

Tratados Hipocráticos, 1986: sSobre Los aires, las aguas y los lugares", Madrid: Gredos, II, 39-88.

WEAR, ANDREW, 1992: "The Popularization of Medicine in Early Modern England", en PORTER (comp.), The Popularization of Medicine 1650-1800, London: Routledge, 17-41.

En este artículo los autores exploran los usos "políticos" del concepto de medicina popular. Desde una posición cercana a la antropología crítica de la medicina, se analiza el surgimiento del concepto a partir de la obra de Pitré, la apropiación de la noción por la etnomedicina, la posterior crítica de los antropólogos de la medicina y, en última instancia, su particular resurgimiento en la antropología italiana y mejicana. De esta exposición crítica emerge una reflexión final sobre el concepto de medicina popular en el contexto de la situación socio-sanitaria actual y las diferentes alternativas posibles.

In this paper the authors explore the 'political' usages of the folk-medicine concept. From a critical medical anthropology approach they analyze the emergent notion in Pitré's work, its later appropiation by the ethnomedicine, the medical anthropology critique and, finally, its new usage in the Italian and Mexican anthropology. As a final remark, they talk about the role of anthropology in the present-day health-care contexts and the different possibilities that this situation brings about in relation with the notion of folkmedicine. 